\title{
Sexualidade e surdez: um diálogo a partir de Michel Foucault
}

\author{
Sexuality and deafness: a dialogue from Michel Foucault \\ Sexualidad y sordera: un diálogo de Michel Foucault
}

Recebido: 00/12/2021 | Revisado: 00/01/2022 | Aceito: 10/01/2022| Publicado: 12/01/2022

\author{
Jakellinny Gonçalves de Souza Rizzo \\ ORCID: https://orcid.org/0000-0002-1721-5572 \\ Universidade Federal de Mato Grosso do Sul, Brasil \\ E-mail: jake.librasufgd@gmail.com \\ Josiane Peres Gonçalves \\ ORCID: https://orcid.org/0000-0002-7005-849X \\ Universidade Federal de Mato Grosso do Sul, Brasil \\ E-mail: josiane.peres@ufms.br
}

\begin{abstract}
Resumo
O presente artigo objetiva desenvolver uma problematização quanto as questões relacionadas à sexualidade da pessoa surda sob a ótica dos estudos foucaultianos. Para tanto, realizou-se uma revisão de literatura, de cunho qualitativo. A pesquisa recorreu a uma investigação nas bases no Portal de Periódicos da Capes - teses e dissertações, no Scientific Electronic Library Online - Scielo e Google Acadêmico, com recorte temporal nos últimos onze anos (2010-2021). No total, foi identificado apenas um estudo que investiga a mesma vertente proposta nesse estudo. Em suma, percebeu-se que a sexualidade dos surdos ainda é tratada na perspectiva biológica, de forma prescritiva e reguladora, em que os sujeitos são referidos como incapazes de receber informações e experimentar relações afetivas e eróticas no seu cotidiano. Ademais evidenciou-se a inexistência de estudos que tratam à temática, o que confirma a necessidade da sistematização de pesquisas nesse âmbito, com o intuito de proporcionar avanços nos trabalhos foucaultianos acerca da sexualidade da comunidade surda.
\end{abstract}

Palavras-chave: Sexualidade; Surdez; Michel Foucault; Pesquisa em educação.

\begin{abstract}
This article aims to develop a problematization of issues related to the deaf person's sexuality from the perspective of Foucault's studies. Therefore, a literature review of a qualitative nature was carried out. The research resorted to an investigation of the bases in the Capes Journal Portal - theses and dissertations, in the Scientific Electronic Library Online - Scielo and Academic Google, with a time frame over the last eleven years (2010-2021). In total, only one study was identified that investigates the same strand proposed in this study. In short, it was noticed that the sexuality of deaf people is still treated from a biological perspective, in a prescriptive and regulatory way, in which subjects are referred to as incapable of receiving information and experiencing affective and erotic relationships in their daily lives. Furthermore, the inexistence of studies dealing with the theme was evidenced, which confirms the need to systematize research in this area, with the aim of providing advances in Foucault's work on the sexuality of the deaf community. Keywords: Sexuality; Deafness; Michel Foucault, Research In Education.
\end{abstract}

Keywords: Sexuality; Deafness; Michel Foucault; Research in education.

\section{Resumen}

Este artículo tiene como objetivo desarrollar una problematización de temas relacionados con la sexualidad de la persona sorda desde la perspectiva de los estudios de Foucault. Por tanto, se realizó una revisión de la literatura de carácter cualitativo. La investigación recurrió a una investigación de las bases en el Portal de la Revista Capes - tesis y disertaciones, en la Scientific Electronic Library Online y Google Académico, con un marco temporal de los últimos once años (2010-2021). En total, solo se identificó un estudio que investiga la misma línea propuesta en este estudio. En definitiva, se advirtió que la sexualidad de las personas sordas aún es tratada desde una perspectiva biológica, de forma prescriptiva y regulatoria, en la que se refiere a los sujetos como incapaces de recibir información y experimentar relaciones afectivas y eróticas en su vida cotidiana. Además, se evidenció la inexistencia de estudios que abordan el tema, lo que confirma la necesidad de sistematizar las investigaciones en esta área, con el objetivo de brindar avances en el trabajo de Foucault sobre la sexualidad de la comunidad sorda.

Palabras clave: Sexualidad; Sordera; Michel Foucault; Investigación en educación. 


\section{Introdução}

O estudo sobre sexualidade é emergente, e os seus efeitos são resultados de pesquisas em diversos contextos, com pessoas idosas (Costa, 2021; Souza Júnior et al., 2022), na perspectiva de jovens (Martínez-Gómez et al., 2021; Nascimento et al., 2020), de pessoas com deficiência (Serra et al., 2020) e, na dinâmica de gênero em contexto internacional (Kunin, 2021). O presente manuscrito tem como objetivo fazer uma caracterização referente ao cenário das pesquisas sobre a sexualidade da pessoa surda sob um olhar dos estudos Foucaultianos.

A sexualidade se dá através de inúmeras aprendizagens e práticas, ela é compreendida de maneira dissimulada ou explícita por um conjunto inesgotável de instância sociais e culturais (Louro, 2008). Trata-se de um processo sutil, minucioso, algo sempre inacabado, desse modo, a construção da sexualidade se dá infindavelmente, ao longo de toda a vida. A sexualidade é, portanto, construída historicamente (Focault, 1988).

A sexualidade não é exclusivamente natural, ela envolve fantasias, linguagens, rituais, símbolos, representações e diversas possibilidades de expressar os desejos e prazeres, os corpos ganham sentido socialmente, compostos e definidos por relações sociais, moldados pelas redes de poder de uma sociedade (Louro, 2000).

Embora tratar sobre a sexualidade da pessoa surda seja uma temática muito importante, ela ainda é marcada por mitos e tabus, pois, como nos diz Maia (2006, 2011), todos aqueles que fogem dos padrões de normalidade são impostas crenças, mitos e concepções ligadas à proibição do prazer sexual, desconsiderando a capacidade de amar e do desejo atribuído a todos os seres humanos.

Nesse viés, Guimarães et al. (2019), em uma pesquisa desenvolvida com universitários surdos, notou as dificuldades enfrentadas pelos participantes no que diz respeito à obtenção das informações sobre a sexualidade. Salienta ainda a importância da participação das famílias e da continuação da disseminação de informações sobre a sexualidade na fase adulta para ampliarem os conhecimentos sobre a sexualidade, com o intuito de desmistificar e abordar os anseios e dúvidas acerca desta temática e auxiliar o desenvolvimento salutar desses jovens.

À vista disso, realizou-se uma revisão de literatura para identificar os trabalhos relacionados à sexualidade da pessoa surda, fundamentados nos escritos de Michel Foucault, autor de grande magnitude na área da sexualidade. A investigação acerca das pesquisas pertinentes a essa temática poderá contribuir para a identificação das lacunas existentes nesse contexto, isto posto, cabe salientar que este manuscrito indica a carência de estudos sobre as questões relacionadas a sexualidade da pessoa surda a partir de Foucault.

\subsection{Um Breve Histórico da Educação de Surdo}

Inicialmente é necessário entender que a história é o passado a desembocar no presente (Febvre, 2000) e, para elaboração do futuro, a história pode e deve ter um grande papel na realidade e continuidade da evolução das próprias bases da ciência.

$\mathrm{Na}$ antiguidade os surdos eram todos vistos como débeis mentais, criminosos, loucos, selvagens, comparados até aos animais selvagens. Os sinais eram tidos como formas obscenas e pecaminosas. Muitas vezes, quando utilizados pelos surdos, eram associados a um espírito do mal. Diante desse cenário, essas pessoas eram empurradas para o contexto patológico, num enquadre ideológico dominante de viés oralista, isso causou impacto e proporções catastróficas na vida e formação educacional dos surdos (Gesser, 2012).

Na Idade Moderna, a partir do século XVI, a educação de surdos teve origem na Espanha, por meio dos trabalhos desenvolvidos pelo monge Benedito Pedro Ponce de León com a fundação da primeira escola para surdos em um monastério de Valladolid. Nesta instituição, inicialmente, o monge ensinava latim, grego, italiano, conceitos de física e astronomia à dois irmãos 
surdos, membros de uma importante família de aristocratas espanhóis. Ponce de Leon usava como metodologia a dactilologia ${ }^{1}$, escrita e oralização (Strobel, 2009), por isso ficou reconhecido por enfatizar o ensino da fala, recebendo os créditos de primeiro professor de surdos ao desenvolver um alfabeto manual.

O alfabeto manual é utilizado para soletrar manualmente as palavras (também conhecido como soletramento digital ou datilologia), é apenas um recurso utilizado por falantes da língua de sinais. Não é uma língua, e sim um código de representação das letras alfabéticas (Gesser, 2009, p. 28).

Conforme Goldfeld (1997), no ano de 1620, também na Espanha, Juan Martin Pablo Bonet, um padre espanhol, educador e pioneiro da educação de surdos, publica um livro que discutia a respeito do alfabeto manual, "Redação das Letras e Artes de ensinar os mudos a falar". Iniciou seus trabalhos na área da educação de surdos, com o nobre Dom Luís Velasco, por meio dos sinais, treinamento da fala e o uso da datilologia.

O século XVIII é considerado o mais fértil da educação de surdos. Nesse período surgiram diversos educadores, desenvolvendo várias metodologias para atender as especificidades das pessoas com surdez, como o abade Charles Michel De L'Epée.

O abade que morava em Paris foi personagem importante na história da educação dos surdos, que a partir de estudos dos sinais usados pelos surdos nas ruas de Paris, criou os "sinais metódicos", com o objetivo de ensinar os surdos parisienses a ler e escrever a língua francesa (Lacerda, 1998).

De L'Epée ministrou aula de educação religiosa em Paris para duas irmãs gêmeas. O processo de aprendizagem proposto previa que os educadores teriam que aprender os sinais com os surdos. Preliminarmente era feita uma combinação dos sinais dos surdos e os sinais inventados pelo abade. Como sucessor o abade contou com a ajuda de Sicard, quem escreveu o primeiro dicionário de sinais.

Em 1760 De L'Epee funda a primeira escola pública para surdos, o Instituto Nacional de Surdos Mudos, em Paris, no qual eram utilizados os sinais metódicos. Em 1789 ele morre, durante sua vida fundou 21 escolas para surdos em várias partes da Europa.

Outros métodos de ensino que não priorizavam a língua de sinais, ainda subsistiam pelo mundo. Em 1778, na Alemanha, cria-se uma escola em Leipzig, por Samuel Heinick, a primeira escola com base na educação oralista, rejeitando a língua de sinais, seu objetivo era desenvolver a fala. Ele ficou conhecido como pai do método alemão.

Já na idade contemporânea, destaca-se o americano Thomas Hopkins Gallaudet, que viajou até a Inglaterra para se encontrar com Thomas Braidwood, quem fundou a primeira escola para surdos no Reino Unido, em busca de metodologias para educação de surdos. A missão de Gallaudet foi frustrada, diante da recusa de Braidwood de compartilhar suas informações pedagógicas com o estrangeiro americano.

Então, parte para Paris em busca dos métodos de ensino aos surdos de De L'Epee. Gallaudet volta à América trazendo o surdo Laurent Clerc, membro do Instituto Nacional para Surdos Mudos. Juntos fundam no ano de 1817 em Hartfort, a primeira escola permanente para surdos nos Estados Unidos (Strobel, 2009). Anos mais tarde seu filho Edward Gallaudet funda a primeira faculdade para surdos, localizada em Washington.

No Brasil, a educação de surdos teve início durante o segundo império, em 1855, quando o imperador Dom Pedro II convidou o professor francês Ernest Huet, que era surdo, para trabalhar na área da surdez. Fundaram juntos a primeira escola para pessoas surdas, Imperial Instituto dos Surdos-Mudos, atual Instituto Nacional de Educação de Surdos - INES, em Rio de Janeiro (Gesser, 2009).

\footnotetext{
${ }^{1}$ Representação manual das letras do alfabeto (Strobel, 2009).
} 
Em Mato Grosso do Sul, somente no ano de 1986 funda-se a primeira escola para surdos do Estado, o Centro Estadual de Atendimento ao Deficiente da Audiocomunicação (CEADA), em Campo Grande, capital de MS.

Um dos fatos mais marcantes na história da Educação de Surdos ocorreu no Congresso de Milão no ano de 1880, no qual, por meio de uma votação com maioria de professores ouvintes, ficou decidido que a Língua de Sinais seria abolida da Educação de Surdos, prevalecendo o uso da Língua Oral.

Uma das grandes figuras presentes no Congresso foi Alexandre Grahan Bell, logo sua influência na sociedade contribuiu para a negação e opressão da língua de sinais. O Oralismo tinha como premissa fazer trabalhos em torno da recuperação da fala e da audição dos surdos, além de repudiar e proibir o uso da língua de sinais. A decisão do Congresso de Milão é apenas um fragmento da história, mas marcou centenas de milhares de vidas de surdos por todo o mundo, deixando rastros de vergonha, lamentação, vingança, recalque e ódio (Gesser, 2012).

O Oralismo no Brasil foi difundido por volta do ano de 1911. Contudo, a Filosofia oralista não estava garantindo a qualidade na educação dos surdos, diante das dificuldades em receber instrução formal os surdos começaram a desenvolver formas de resistências, como criação de associações de surdos, realização de casamentos endógamos, manifestações culturais.

Alguns profissionais perceberam um papel relevante da língua de sinais no processo de escolarização dos surdos, e que poderiam ter sérias implicações não somente linguísticas, mas também psicológicas e sociais se fossem submetidos ao oralismo. Assim, timidamente começou a disseminar a chamada Comunicação Total, que privilegiava qualquer tipo de comunicação. Reconhecia a diferença linguístico-cultural, mas utilizavam os sinais para desenvolver a fala (Gesser, 2012). Começou a ser usada no Brasil por volta do ano de 1960.

Pode-se perceber claramente que as abordagens por meio do Oralismo e da Comunicação Total não obtiveram êxito, pois tinham como objetivo adaptar as pessoas com surdez à realidade dos ouvintes. Foi então que na década de 80 surge a abordagem Bilíngue em favor de melhorias na educação de surdos.

A proposta baseia-se na perspectiva de educação voltada para as duas línguas, a Libras (Língua Brasileira de Sinais) como sua primeira Língua (L1) dos surdos, que embora já fosse utilizada pelos surdos foi oficializada no Brasil em 2002, pela Lei $\mathrm{n}^{\circ}$ 10.436/02 e, posteriormente regulamentada pelo decreto 5.626/05 e a Língua Portuguesa, como segunda Língua (L2) na modalidade escrita (Brasil, 2004).

$\mathrm{Na}$ atualidade, os estudos estão voltados para o fenômeno do bilinguismo. Sendo assim, "[...] o respeito às diferenças linguísticas e culturais e, especialmente, aos direitos das minorias, nunca tiveram ênfase tão grande quanto nos tempos atuais" (Gesser, 2012, p. 88).

Em relação à educação de surdos atualmente, nota-se que houveram avanços e um maior reconhecimento pela sociedade. Uma das conquistas da comunidade surda foram as mudanças implementadas na edição do Enem 2017, com aplicação de provas em Libras, um recurso de acessibilidade para realização do exame por surdos e pessoas com deficiência auditiva, destaca-se ainda o tema da redação: "Desafios para Formação Educacional de Surdos".

Conforme essas premissas, nota-se que a história da educação de surdos no Brasil e no mundo passou por quase cem anos de imposição do Oralismo, perpassando pela comunicação total até o bilinguismo, uma realidade brasileira arduamente construída ao longo da história.

A construção dessas políticas para pessoas surdas no Brasil está em processo, contudo, os movimentos surdos conquistaram grandes avanços, como o reconhecimento da Libras, que é considerado uma referência de democracia, pois desde o reconhecimento das necessidades e diferenças, e a oficialização da língua de sinais, a comunidade surda passou a agir e ser protagonista da sua história. 


\subsection{História da sexualidade na perspectiva de Foucault}

Michel Foucault, nascido em 15 de outubro de 1929, em Poitiers, França, foi um influente filósofo do século XX. Sua família era composta por inúmeros médicos, contudo, desde cedo recusou a medicina, pois já no ensino básico se interessava por filosofia. Foi um filósofo, psicólogo, professor e escritor que revolucionou as estruturas filosóficas do século XX. Foi considerado um dos filósofos contemporâneos mais polêmicos, devido ao olhar crítico de si mesmo, e em 1984 morre, vítima da Aids.

Por conta de suas tentativas de suicídio, aproximou-se da psicologia e psiquiatria, chegou a trabalhar como psicólogo patologista em vários presídios e hospitais psiquiátricos, o que contribuiu para a construção de diversos escritos como Vigiar e Punir e História da Loucura.

Publicou inúmeras obras, dentre elas a "História da Sexualidade" que discute sobre a sexualidade no mundo ocidental. A obra divide-se em três tomos: A vontade de saber (1988), O uso dos prazeres (1984) e O cuidado de si (1984). As confissões da Carne seria seu último volume da História da Sexualidade, contudo, este não foi concluído em decorrência da morte do filósofo.

Logo nas primeiras páginas de “A vontade de saber”, Foucault (1988) já começa dizendo que no início do século XVII as práticas não procuram o segredo, não havia vergonha nos discursos, as anatomias eram mostradas e facilmente misturadas, as crianças eram astutas, sem escândalos e nem incômodos. Em um rápido crepúsculo, a sexualidade é cuidadosamente encerrada, então, na era vitoriana, a moral burguesa conduziria a sexualidade para dentro de casa, confiscada para o seio família conjugal heterossexual, e passa a ter inteiramente a função de reproduzir.

Foucault discorre sobre a hipótese repressiva da sexualidade, no século XVII iniciaria uma época de repressão própria das sociedades que eram chamadas de burguesas, assim, a partir desse momento, seria mais difícil e custoso denominar o sexo. Temiam chamá-lo pelo nome, não era permitido falar sobre ele, a não ser exclusivamente para falar de sua proibição, impondo o silêncio e a censura, como símbolo de repressão e interdição do sexo.

A repressão da sexualidade passa a funcionar como formas de inexistência, silenciamento e interdição das práticas sexuais, que eram na época consideradas como ilegítimas, pois não atendiam ao modelo heterossexual da família reprodutora.

Para Foucault (1988), desde a época clássica, a repressão foi o modo fundamental de ligação entre poder, saber e sexualidade. Na modernidade do ocidente, o regime de poder e saber está na base de discursos que lidam com a sexualidade. "Parece-me que se deve compreender o poder, primeiro como a multiplicidade das relações de força imanentes ao domínio onde elas se exercem, e são constitutivas de sua organização" (Foucault, 1988, p. 88). Para o autor, o poder parece estar em todos os domínios da vida social, o poder está por toda parte, não que englobe tudo, mas sim, ele vem de toda parte.

Intimamente ligado ao poder, Foucault aponta em seus escritos o que ele denominou de Scientia Sexualis ${ }^{2}$, que foi "desenvolvida a partir do século XIX, paradoxalmente, guarda como núcleo o singular rito da confissão obrigatória e exaustiva, que constituiu, no Ocidente cristão, a primeira técnica para produzir a verdade do sexo" (Foucault, 1988, p. 66). A produção da sexualidade foi o resultado em desenvolver essa ciência. Portanto, para Foucault, a Scientia Sexualis busca a produção da verdade sobre o sexo.

A confissão passou a ser considerada, no Ocidente, uma das técnicas altamente mais valorizada para se produzir a verdade, qual teve seus efeitos difundidos amplamente, na justiça, na pedagogia, na medicina, nas relações familiares, nas relações amorosas, e nos contextos mais solenes. Nota-se, dessa forma, que o mecanismo de poder que é desenvolvido na Scientia Sexualis não é contrário ao prazer, mas produtor dele também, assim, o poder no sexo não deve ser analisado a partir da repressão,

\footnotetext{
${ }^{2}$ Ciência sexual, ciência do sexo que tinha o papel da confissão, do falar, com o objetivo de produzir conhecimento sobre o sexo. (Foucault, 1988).
} 
pelo contrário, deve ser analisado pela própria incitação. "Nós dizemos a sua verdade, decifrando o que dela ele nos diz, e ele nos diz a nossa, liberando o que estava oculto". (Foucault, 1988, p. 98).

Para Foucault (1988), as relações de sexo em toda sociedade deram lugar a um dispositivo de aliança, um sistema de matrimônio, de desenvolvimento de parentescos, de fixação, de transmissão de nomes e bens, apto ao vínculo entre parceiros, com status definido, seu momento decisivo é a reprodução.

Contudo, a partir do século XVIII, as sociedades ocidentais modernas instalaram um novo dispositivo que se superpõe ao primeiro, assim é criado o dispositivo da sexualidade, este se articula aos parceiros sexuais, funciona de acordo com técnicas móveis, polimorfas e conjunturais de poder. Uma extensão permanente dos domínios e das formas de controle, pertinente às sensações do corpo, a qualidade do prazer, o corpo é o centro, o dispositivo da sexualidade tem como razão de ser, de se inovar, inventar, de penetrar nos corpos de maneira cada vez mais detalhada.

O estudo da sexualidade descrito na obra de Michel Foucault, História da sexualidade, expõe a importância do momento histórico, político e social, para se formar conceitos como sexualidade. Demonstra a importante influência das relações de poder para a formação da subjetividade dos indivíduos no contexto social.

Destarte, Foucault evidencia ainda que a sexualidade não é natural, e sim histórica, pois é construída historicamente, algo que pode ser alterado, não estamos sujeitos a viver com a sexualidade que foi produzida e é oferecida a nós como natural, podemos criar nossa própria sexualidade, centrando-se no próprio corpo, desejos e prazeres.

\subsection{Interfaces entre Sexualidade e Surdez}

Em 2019, segundo Nascimento (2020), um estudo feito em conjunto pelo Instituto Locomotiva e a Semana da Acessibilidade Surda revela a existência de 10,7 milhões de pessoas surdas ou com deficiência auditiva no Brasil.

Os surdos vivem em uma sociedade majoritariamente de pessoas ouvintes, e se deparam diariamente com as barreiras linguísticas e culturais, por serem minoria linguística, visto que se comunicam por meio da Libras, língua oficial no Brasil, reconhecida pela Lei 10.436/02, como meio legal de comunicação e expressão em todo território nacional (Brasil, 2002), e regulamentada pelo Decreto Federal 5.626/05 (Brasil, 2005).

Lebedeff (2010) afirma que os surdos enfrentam problemas de acesso a informações sobre a sexualidade, não porque a surdez seja um impedimento ao conhecimento, mas porque a sociedade limita-os de condições e espaços para a educação sexual.

Nesse bojo, as informações que as pessoas surdas recebem sobre a sexualidade são escassas, marcadas por mitos e tabus, os sujeitos surdos chegam a serem vistos como assexuados, como se a surdez fosse sinônimo de incapacidade de exercer a sexualidade permanente.

Contudo, Glat (2004) afirma que semelhanças são encontradas na sexualidade dos jovens surdos e ouvintes, no entanto, o que difere é o acesso às informações e os preconceitos existentes acerca das expressões da sexualidade.

A construção da sexualidade se dá ao longo de toda a vida, continuamente, infinitamente, construída culturalmente, podemos criar a nossa própria sexualidade, algo que pode ser alterado (Foucault, 1988; Louro, 2008).

Para Dreyer et al. (2018), a sexualidade é manifestada de diferentes formas a cada etapa do desenvolvimento humano, sendo construída ao longo da vida. Encontra-se necessariamente marcada pela cultura, história, ciência, bem como pelos afetos e sentimentos. Portanto, é possível concluir que a expressão da sexualidade acontece de forma distinta para cada sujeito, ou seja: é uma expressão cultural.

A sexualidade da pessoa surda desenvolve-se como a do ouvinte, a carência de informação a respeito da temática. Segundo Abreu (2011), advém da falta de comunicação, tanto pela falta de fluência em Libras quanto no silenciamento familiar acerca das discussões e orientações que envolvem temas relacionados à sexualidade, é fator prejudicial para uma orientação sexual efetiva. 
Frequentemente a sexualidade é vista somente como o ato sexual, como Dreyer et al. (2018), observou em uma pesquisa com o objetivo de identificar a opinião de jovens surdos sobre os assuntos relacionados a sexualidade, constatou que todos os entrevistados, tem o conhecimento limitado apenas a conceitos associados a "sexo", gravidez, valores morais e doenças. Todavia, a sexualidade é algo muito além disso, Maia (2008) comenta que a sexualidade é um conceito muito abrangente, que inclui aspectos da genitalidade, no entanto, não se resume a isso. Ademais, diz respeito a sentimentos, emoções, prazeres, erotismo libidinal envolto nas relações interpessoais, que incluem ou não o relacionamento sexual entre sujeitos.

Neste seguimento, Guimarães e Silva (2020) realizaram um estudo sobre as representações sociais dos estudantes surdos sobre sexualidade, os resultados apontaram que os participantes consideram a sexualidade ancorada à saúde sexual, relações com os seus pares e nas relações íntimas de afeto. Salientam a barreira linguística entre os familiares, o que pode impedir o acesso a informações, destacam ainda essa mesma barreira nas propagandas televisivas sobre a temática, em razão das dificuldades dos surdos com o português escrito e, ressaltam a necessidade da presença do Tradutor Intérprete de Língua de Sinais (TILS) nestas propagandas.

Nessa conjuntura, nota-se que a sexualidade das pessoas surdas não se difere da dos ouvintes, contudo, os ouvintes têm mais acesso ao conhecimento relacionado a essas questões, e as informações que chegam aos surdos são diferentes, muitas vezes insuficientes, seja pela falta do acesso linguístico, ou até mesmo por acreditarem que são assexuados, pois a comunidade surda é marcada por uma diferença que muitas vezes a discrimina e a segrega.

\section{Metodologia}

Com o propósito de apresentar algumas reflexões sobre a Sexualidade da pessoa surda sob um olhar Foucaultiano, realizou-se uma pesquisa com abordagem qualitativa, da qual Cezar $(2009$, p. 142) afirma que "possibilita o atendimento a investigação específica, uma vez que ela permite mergulhar no mundo dos significados, dos sentidos, das ações, das convicções e dos comportamentos humanos", "desenvolvida com base em material já elaborado constituído principalmente de livros e artigos científicos" (Gil, 2002, p. 44).

Para a realização do presente estudo, foi realizada uma investigação nas bases no Portal de Periódicos da Capes - teses e dissertações, no Scientific Electronic Library Online - Scielo e Google Acadêmico.

Os critérios de inclusão utilizados na busca foram os estudos publicados com recorte temporal de 2010 a 2021, incluindo pesquisas realizadas com humanos, publicadas em língua portuguesa. Como estratégia de busca, foram utilizaram os seguintes descritores em português: "Sexualidade", "Surdez", "Michel Foucault".

Para a seleção dos artigos considerou inicialmente os títulos dos trabalhos, em seguida os resumos dos estudos, com o objetivo de verificar se os mesmos contemplavam a intenção desta revisão, e por fim, uma revisão completa do texto. Na intenção de obter um número relevante de referencial teórico, não foi limitado idioma para a seleção. Foram excluídos todos os trabalhos que não constituíram nenhuma relação com o tema proposto nesta revisão.

Foram analisadas teses, dissertações, artigos científicos e revistas, por meio de um levantamento bibliográfico, a qual Gil (2002, p. 45) considera "[...] uma das mais importantes fontes bibliográficas", pois permite que o pesquisador obtenha de todo lugar do mundo, diferentes informações sobre determinada temática.

Com relação a abordagem qualitativa, Minayo (2002) diz que essa metodologia responde a questões particulares; preocupa-se com um nível de realidade que não pode ser quantificado; trabalha com um universo de significados, motivos, aspirações, crenças, valores, atitudes, o que corresponde a um espaço mais profundo das relações, dos processos e dos fenômenos que não podem ser reduzidos à operacionalização de variáveis.

Durante o processo de seleção, bem como nas análises e discussões dos estudos, buscou-se responder aos seguintes questionamentos: Qual o objetivo da pesquisa? Qual a metodologia utilizada? Quais os resultados obtidos? 
Após o processo de refinamento, excluíram-se estudos que não atendiam aos critérios de seleção, que foram lidos e explorados cuidadosamente, logo, selecionou-se apenas um estudo que respondia aos critérios de inclusão estabelecidos e constituíram a amostra dessa investigação.

\section{Resultados e Discussão}

No Portal do Catálogo de Teses e dissertações quando foram inseridos os descritores separadamente, obteve o resultado de 6591 estudos para "Sexualidade", "Surdez" 1562 e para "Michel Foucault" 15104. Ao inserir os descritores simultaneamente "Sexualidade", "Surdez", "Michel Foucault" sem refinamento, resultaram em 11920 e ao refinar os resultados na Grande área de conhecimento - Ciências humanas, Área conhecimento - Educação, Área avaliação - Educação, Área de concentração Educação, e Nome do programa - Educação, resultaram em 1069 estudos, nesse banco de dados, contudo nenhuma pesquisa atendia aos critérios de seleção.

Ao inserir o descritor "Sexualidade" no Scielo, constatou-se 2105 registros, "Surdez" 459 e "Michel Foucault" 959 estudos. Ao inserir os descritores combinados Sexualidade and Surdez and Michel Foucault, não foram encontrados documentos para a pesquisa. Com o intuito de encontrar estudos que atendessem os critérios de inclusão combinou-se "Sexualidade" and "Surdez", qual resultou somente em 3 estudos, "Sexualidade" and "Michel Foucault" 42, e para "Michel Foucault" and "Surdez" foram contatados 2 pesquisas.

No portal Google acadêmico o descritor "Sexualidade" resultou em 71.300 estudos, "Surdez" 17. 200 e "Michel Foucault" 337.000. Ao inserir os três descritores concomitantemente, obteve-se o total de 642 trabalhos. Desses trabalhos, apenas um acatava aos critérios de inclusão, qual será apresentado no quadro 1 a seguir.

Quadro 1. Estudo selecionado no Google acadêmico

\begin{tabular}{|l|l|l|l|l|}
\hline \multicolumn{2}{|c}{ Autores } & Título & Tipo & Ano \\
Witchs, Pedro Henrique & $\begin{array}{c}\text { Gênero e sexualidade em } \\
\text { educação de surdos }\end{array}$ & Artigo & 2017 & $\begin{array}{c}\text { Revista ECS - } \\
\text { Educação, Cultura } \\
\text { e Sociedade. }\end{array}$ \\
\hline
\end{tabular}

Fonte: Elaborado pelas autoras (2021).

Ao realizar o levantamento bibliográfico é possível identificar uma pesquisa que aborda a temática proposta nesse manuscrito, ou seja, a sexualidade da pessoa surda a partir de estudos Foucaultianos.

O artigo teve como objetivo problematizar a relação de gênero e sexualidade na educação de surdos, numa perspectiva pós-estruturalista de inspiração Foucaultiana. Para isso, Witchst (2017) realizou uma breve contextualização das relações de gênero e sexualidade na história da educação de surdos, logo o autor analisa cenas contemporâneas evidenciadas em uma escola de surdos, período em desenvolveu atividades enquanto professor estagiário de Ciência, momento em que passou a discutir questões relacionadas a gênero e sexualidade em uma turma de $7^{\mathrm{a}}$ série (atual $8^{\circ}$ ano).

Witchst (2017) pensa a surdez como uma matriz de experiência. Contudo, não apenas a surdez, deve ser vista dessa maneira, uma vez que o gênero e a sexualidade também podem ser entendidos como formas históricas de subjetivação, modo como Foucault (2006) criou o conceito de experiência no desenvolvimento de sua obra.

Nesse sentido, é necessário compreender a subjetivação como "o processo pelo qual se obtém a constituição de um sujeito, mais precisamente de uma subjetividade, que [...] não passa de uma das possibilidades dadas de organização de uma consciência de si" (Foucault, 2006, p. 262).

No transcorrer do texto Witchst (2017) expõe alguns dos episódios ocorridos durante sua experiência, qual ele chama de cenas contemporâneas na escola de surdos, como é possível ver na cena 1 abaixo. 
Cena 1

- Professor, tenho uma pergunta. O que vou perguntar não aconteceu, é só uma questão hipotética: dois homens apaixonados um pelo outro podem fazer sexo anal?

- Sim, podem sim.

$\mathrm{O}$ aluno surdo demonstra-se surpreso com a resposta do professor e rapidamente compartilha a informação com o colega ao seu lado que reage incrédulo: - Mentira!.

- É verdade, foi o que o professor disse! — o aluno responde e ambos se viram para o professor para que ele confirme o que disse. (Wichst, 2009, apud Wichst, 2017).

Para Witchs (2017, p. 82), “as reações de espanto expressadas pelos dois alunos talvez sejam representações da ideia de que o sexo, quando praticado em uma relação homossexual, não possa estar atrelado ao desejo natural". Dessa forma, a imagem do sujeito homossexual fortalecida pelo pensamento de que a homossexualidade seja um distúrbio, uma patologia, uma perversão, flutua por aquela cena.

O autor supracitado considera que o contexto em que questões sobre gênero e sexualidade estejam articulados à história da educação de surdos requer estudos mais aprofundados, de modo que cenas semelhantes as apresentadas em seu estudo sejam conduzidas e interpretadas de maneira ética, profissional e qualificada.

Nessa conjuntura, a partir dos resultados apresentados no quadro 1, em consonância com as considerações de Witchs (2017), percebe-se a necessidade de intensificar pesquisas sobre a temática que envolve a Sexualidade da pessoa surda em um viés Foucaultiano, uma vez que podem contribuir para a problematizar as discussões nessa perspectiva.

\section{Considerações Finais}

Historicamente a surdez foi uma classe narrada pelas normas dos ouvintistas, marcada culturalmente por características consideradas desvantajosas, o que fez com que a comunidade surda fosse silenciada por muito tempo por não estar dentro dos padrões esperados pela sociedade.

A sexualidade das pessoas surdas é marcada por muitos mitos e preconceitos, chegando muitas vezes a serem consideradas assexuadas. A sexualidade dos surdos ainda é tratada na perspectiva biológica, de forma prescritiva e reguladora, em que os sujeitos são referidos como incapazes de receber informações e experimentar relações afetivas e eróticas no seu cotidiano. Contudo, os interesses das pessoas surdas são iguais aos das demais pessoas, como afetos, namoro, relações sexuais. Dessa forma, o intuito deste manuscrito foi problematizar a sexualidade da pessoa surda fundamentando-se nas produções de Michel Foucault, autor renomado no âmbito da história da sexualidade.

Embora seja uma temática relevante para ser discutida, os estudos no tocante a sexualidade do surdo ainda são escassos no Brasil (Abreu, 2015). Os resultados desta pesquisa vão de encontro com a fala do autor supracitado, pois na busca por trabalhos que discutem essa vertente, no Portal de Periódicos da Capes - teses e dissertações, no scientific electronic library online - Scielo e Google Acadêmico, utilizando os descritores "Sexualidade", "Surdez", "Michel Foucault", apenas um estudo atendeu aos critérios de inclusão.

Dessa forma, este estudo denuncia à carência de pesquisas no tocante a sexualidade da pessoa surda, bem como advogase a necessidade futuras pesquisas neste seguimento, pois discutir essas questões torna-se relevante para que a comunidade surda possa problematizar sua sexualidade, numa perspectiva prazerosa, e desse modo, romper com os tabus e estigmas que permeia sobre a sexualidade desses sujeitos. Assim, futuros estudos podem investigar a sexualidade do surdo como um componente multidimensional a partir de diferentes abordagens filosóficas.

\section{Agradecimentos}

CAPES - Coordenação de Aperfeiçoamento de Pessoal de Nível Superior e ao Grupo de Estudo e Pesquisa em Desenvolvimento Gênero e Educação (GEPDGE). 


\section{Referências}

Abreu, F. S. D. (2011). Vozes silenciadas. http://bdm.unb.br/bitstream/10483/3270/1/2011_FabricioSantosDiasdeAbreu.pdf.

Abreu, F. S. D. (2015). Experiências linguísticas e sexuais não hegemônicas: um estudo das narrativas de surdos homossexuais. [Dissertação de mestrado]. Programa de Pós-Graduação em Processos de Desenvolvimento Humano e Saúde, Universidade de Brasília.

Brasil. Ministério da Educação. (2002). Secretaria de Educação Especial. Lei $N^{o}$. 10.436, de 24 de abril de 2002. Dispõe sobre a Língua Brasileira de Sinais LIBRAS. Brasília.

Brasil. (2005). Decreto 5.626. Regulamenta a Lei no 10.436, de 24 de abril de 2002, que dispõe sobre a Língua Brasileira de Sinais - Libras Brasília.

Cezar, E. H. A. (2009). O ensino médio estadual noturno: a consolidação da escola pública como "cortina de fumaça". (ou a ciência não é para todos?). [Tese de doutorado]. Programa de Pós-Graduação em Educação, Universidade Federal de Goiás.

Costa, R. M. P. (2021). Identidades, gêneros, sexualidade e velhice em "Marieta e Ferdinando", de Sérgio Sant'Anna. Revista Brasileira de Literatura Comparada, 23, 192-202. https://doi.org/10.1590/2596-304x20212344rmpc

Dreyer, L. R. O., Mateus, M. A. R.., \& Gonçalves, J. P. (2018). Pessoas com surdez e suas relações com a Sexualidade: silenciamentos e descobertas. Revista Textura (ULBRA), Revista de Educação e Letras. v. 20 n. 44.

Foucault, M. (1988). História da sexualidade I: A vontade de saber. Tradução: Maria Thereza da Costa Albuquerque; José Augusto Guilhon Albuquerque (1999). Rio de Janeiro: Edições Graal.

Foucault, M. (1984). História da sexualidade II: O uso dos prazeres. Tradução: Maria Thereza da Costa Albuquerque (1998). Rio de Janeiro: Edições Graal.

Foucault, M. (1985). História da sexualidade III: O cuidado de si. Tradução: Maria Thereza da Costa Albuquerque (2005). Rio de Janeiro: Edições Graal.

Gesser, A. (2012). O ouvinte e a surdez: sobre ensinar e aprender LIBRAS. São Paulo, Parábola Editorial.

Gesser, A. (2009). Libras? Que língua é essa? Crenças e preconceitos em torno da língua de sinais e da realidade surda. São Paulo: Parábola Editorial.

Gil, A. C. (2002). Como elaborar projetos de pesquisa. (4a ed.), Atlas.

Glat, R. (2004). Saúde Sexual, Deficiência e Juventude em Risco. Rio de Janeiro: Universidade Federal do Rio de Janeiro.

Goldfeld, M. (1997). A Criança Surda: Linguagem e Cognição numa Perspectiva Socio-interativa. Plexus.

Guimarães, V. M. A.., Santos, F., Santos, B. F. S., \& Silva, J. P. (2019). Surdez e sexualidade: Uma análise a partir das representações sociais de universitários surdos. Estudos e Pesquisas em Psicologia, 19(2).

Guimarães, V. M. A., \& Silva, J. P. (2020). Surdez e sexualidade: as representações sociais dos discentes surdos. Arquivos brasileiros de Psicologia, 72(1).

Jesus J. D., \& Fernandes, S. (2017). Educação bilíngue para surdos/as: um estudo comparativo da escola bilíngue e do atendimento educacional especializado (AEE) na escola inclusiva. Revista Ibero-Americana de Estudos em Educação, 12(3), 1628-1648.

Kunin, J. (2021). Los “medio putos”: Masculinidades subalternas y dinámicas de género alternativas en la rural Pampa húmeda argentina (2014-2017). Historia y sociedad, 41, 69-92. https://doi.org/10.15446/hys.n41.92029

Lacerda, C. B. F. (1998.). Um pouco da história das diferentes abordagens na educação de surdos. Caderno Cedes, 19(46).

Lebedeff, T. B. (2010). Surdez e sexualidade: uma discussão sobre a necessidade de empoderamento linguístico e acesso à informação. In: Encontro De Pesquisa Em Educação Da Região Sul, 8, 2010, Londrina. Anais de Londrina: UEL. https://docplayer.com.br/13124540-Surdez-e-sexualidade-uma-discussao-sobre-anecessidade-de-empoderamento-linguistico-e-acesso-a-informacao-tatiana-bolivar-lebedeff-ufpel.html.

Louro, G. L. (2000). Pedagogias das Sexualidades. In: LOURO, Guacira Lopes (Org.). O Corpo Educado. Autêntica, 7-34.

Louro, G. L. (2008). Gênero e sexualidade: pedagogias contemporâneas. Pro-Posições, 19(56), 17-23.

Maia, A. C. B. (2011). Inclusão e sexualidade: Na voz de pessoas com deficiência física.: Juruá.

Maia, A. C. B. (2008). A educação sexual repressiva: padrões definidores de normalidade. In: Souza, C. B. G. de; Ribeiro, P. R. M. (Org.) Sexualidade, Diversidade e Cultura Escolares: contribuições ibero-americanas para estudos de educação, gênero e valores. Araraquara: FCL-UNESP Laboratório Editorial; Alcalá de Henades: Universidad de Alcalá, p. 67-83.

Maia, A. C. B. (2006). Sexualidade e deficiências. Ed. UNESP.

Martínez-Gómez, M. L., Gallo-Restrepo, N. E., Puerta-Henao, E., Martínez-Gómez, M. L., Gallo-Restrepo, N. E., \& Puerta-Henao, E. (2021). Satisfacción en los servicios de salud sexual y reproductiva: Perspectiva de jóvenes. Medellín-Colombia. Hacia la Promoción de la Salud, 26(2), 161-174. https://doi.org/10.17151/hpsal.2021.26.2.12

Minayo, M. C. S. (2002). Pesquisa social: teoria, método e criatividade. (14a ed.),Vozes.

Moreira, S. Z. (2010). A mulher surda e suas relações de gênero e sexualidade. In: Skliar, C. A surdez: um olhar sobre as diferenças Mediação, p. 95-103. 
Research, Society and Development, v. 11, n. 1, e48011121024, 2022

(CC BY 4.0) | ISSN 2525-3409 | DOI: http://dx.doi.org/10.33448/rsd-v11i1.21024

Nascimento, S. T. (2020). "O uso de TDIC no processo de construção da aprendizagem do aluno surdo no ensino superior ". Anais do CIET:EnPED:2020 (Congresso Internacional de Educação e Tecnologias | Encontro de Pesquisadores em Educação a Distância), São Carlos, ago. 2020. https://cietenped.ufscar.br/submissao/index.php/2020/article/view/1537.

Nascimento, M. A. C., Monte, L. M. I., Sousa, R. F. V., Pessoa, B. G. F., Mateus, A. S., \& Nascimento, E. F. do. (2020). Eu Falo, Tu Falas E Ninguém Ouve: Conversas sobre sexo e sexualidade entre adolescentes e jovens no espaço escolar. Research, Society and Development, 9(8), e386985852-e386985852. https://doi.org/10.33448/rsd-v9i8.5852

Quadros, R. M., \& Campello, A. R. S. (2010). A constituição política, social e cultural da língua brasileira de sinais - libras. In: VIEIRA- MACHADO, Lucyenne Matos da Costa; LOPES, Maura Corcini (Org.). Educação de surdos: políticas, língua de sinais, comunidade e cultura surda. Santa Cruz do Sul: EDUNISC, p. $15-47$.

Serra, I. O., Joca, T. T., Oliveira, A. R. M. N., \& Munguba, M. C. (2020). A pessoa com deficiência e os entrelaces com as questões de gênero e de sexualidade. Research, Society and Development, 9(8), e728986157-e728986157. https://doi.org/10.33448/rsd-v9i8.6157

Souza Júnior, E. V., Silva, C. dos S., Pirôpo, U. S., Santos, B. F. M. dos, Guedes, T. P., Siqueira, L. R., \& Sawada, N. O. (2022). Effects of sexuality on frailty and quality of life in the elderly: A cross-sectional study. Revista Brasileira de Enfermagem, 75. https://doi.org/10.1590/0034-7167-2021-0049

Strobel, K. (2009). História da educação dos surdos. UFSC.

Witchs, P. H. (2017). Gênero e sexualidade em educação de surdos. Revista Educação, Cultura e Sociedade. Sinop/MT/Brasil, 7(1), 75-88. 